\title{
JACQUES DERRIDA E NIKLAS LUHMANN: APROXIMAÇÕES E COMPLEMENTARIDADES NA SINGULARIDADE E PODER
}

\author{
Rafael Lazzarotto Simioni ${ }^{1}$ \\ Isabela de Castro Franco ${ }^{2}$
}

\begin{abstract}
Resumo
Essa investigação procura estabelecer uma aproximação dialética entre os conceitos de identidade e singularidade, poder e autoridade, na filosofia desconstrutivista de Jacques Derrida e na teoria dos sistemas sociais autopoiéticos de Niklas Luhmann. Tratam-se de duas importantes concepções teóricas do final do Século XX, muito diferentes em seus pressupostos e objetivos, mas muito próximas em alguns aspectos. Embora as comparações pareçam ficar mais no plano das metáforas do que plano conceitual, tanto Luhmann quanto Derrida permitem uma nova forma de entendimento da singularidade e do poder da autoridade. Pois em ambos a singularidade/identidade só pode ser entendida a partir da alteridade/diferença. De modo que o poder e os paradoxos da autoridade, que historicamente só puderam ser creditados por meio de fundamentos místicos de autoridade, encontram em Luhmann e Derrida a possibilidade de uma fundamentação diferencialista, pós-ontológica, baseada na própria diferença que constitui a sua identidade, na alteridade que confere sentido à singularidade. Com o auxílio das mesmas pode-se ter maior capacidade de atribuir sentido a aparente fragmentação do Estado, especialmente no que tange às suas Instituições e a Representação Política.
\end{abstract}

Palavras-Chave: Jacques Derrida e Niklas Luhmann. Singularidade. Identidade. Poder.Autoridade.

\section{INTRODUÇÃO}

Esse artigo procura estabelecer uma relação exploratória sobre as possibilidades de diálogo entre as noções de singularidade/identidade e de poder/autoridade em duas importantes perspectivas teóricas do final do Século XX: a filosofia desconstrutivista de Jacques Derrida e o construtivismo radical da teoria dos sistemas sociais autopoiéticos de Niklas Luhmann. Com o auxílio das mesmas, ter maior capacidade de atribuir sentido a aparente fragmentação do Estado, no que tange às suas Instituições e a RepresentaçãoPolítica.

Tratam-se de duas concepções teóricas bastante sofisticadas, muito diferentes em seus pressupostos teóricos e conceituais, mas muito semelhantes em alguns aspectos, especialmente no estilo de análise pós-

\footnotetext{
${ }^{1}$ Pós-Doutor em Filosofia do Direito pela Universidade de Coimbra, Doutor em Direito Público pela Unisinos, Mestre em Direito pela UCS, Professor do Programa de Mestrado em Direito da FDSM - Faculdade de Direito do Sul de Minas. E-mail: simioni2010@gmail.com.

${ }^{2}$ Mestranda em Direito pela Faculdade de Direito do Sul de Minas. Graduada em Direito pela PUC-MG. E-mail: isabelacfranco@gmail.com.
} 
ontológica que ambas procuram estabelecer. Tanto o desconstrutivismo de Derrida, quanto o construtivismo radical presente no script que Luhmann chamada de observação de segunda ordem, permitem um potencial crítico e intelectivo muito sensível às estruturas e à dinâmica discursiva da sociedade contemporânea.

Não é por acaso que a marcação de proximidades e divergências entre Luhmann e Derrida é objeto de estudo desde os anos noventa. Naturalmente, tratam-se de perspectivas teóricas tão diferentes que as aproximações parecem se situar mais no plano metafórico do que efetivamente no plano conceitual. A incomensurabilidade dos paradigmas é uma questão que percorre todas as diferenças de linguagem, de objetivos e de modos de reflexão entre a filosofia de Derrida e a teoria dos sistemas de Luhmann. Mas também sabemos que, dentre as redes conceituais nessas duas grandes teorias, há conceitos muito próximos, cuja relação não apenas se torna interessante em termos intelectivos, mas especialmente potente em termos de desconstrução e reconstrução do sentido das práticas discursivas contemporâneas.

Em uma postura radicalmente pós-moderna, negaram ou mesmo abandonaram a ilusão de segurança e verdade. Levando Gunther Teubner a afirmar que a autopoiese e a desconstrução são as mais impactantes irritações teóricas do "Direito e Sociedade" das últimas décadas. ${ }^{3} \mathrm{O}$ que faz serem teóricos pouco compreendidos e, consequentemente, mal interpretados.

De fato, nunca será fácil abandonar a segurança e se lançar ao entendimento de uma sociedade complexa, dotada de infinitas possibilidades, ainda que a teoria dos sistemas pretenda reduzir complexidade, o que, paradoxalmente, a leva a aumentar. Assim, Gunther Teubner, tratando da policontextualidade do direito, afirma que o direito deve abrir os olhos para a ausência de uma racionalidade social compreensível. ${ }^{4}$

Não encontra-se referência de Derrida à Luhmann, todavia encontra-se referências de Luhmann à Derrida. Naturalmente mais em um plano metafórico do que genuinamente conceitual, Luhmann utiliza diversos conceitos de Derrida como estratégia de ilustração e comparação do seu próprio estilo de pensamento. Destacase a obra O Direito da Sociedade, na qual Luhmann faz referências expressas à Derrida, quanto à ideia de suplemento, principalmente, mas também de escritura, origem e fonte, além de citar expressamente a desconstrução e o paradoxo no pensamento deDerrida. ${ }^{5}$

No campo do direito, dois conceitos-chave presentes tanto em Derrida quanto em Luhmann são os conceitos de singularidade/identidade e de poder/autoridade. Naturalmente existem outras correspondências importantes, como a questão da Justiça, a relação entre o conceito de suplemento em Derrida e a metáfora do

\footnotetext{
${ }^{3}$ TEUBNER, Gunther. Justiça Autosubversiva: Fórmula de contingência ou de transcendência do direito?. Revista Eletrônica do Curso de Direito - PUC Minas Serro, Belo Horizonte, n. 4, p. 17 . Disponível em: <http://periodicos.pucminas.br/index.php/DireitoSerro/article/view/2259/2792>. Acesso em 19.05 2015.

${ }^{4}$ Ibidem, p. 42

${ }_{5}^{5}$ LUHMANN, Niklas. El Derecho de la Sociedad. Tradução de Javier Torres Nafarrate. México: Universidad Iberoamericana, 2005 , p. 397.
} 
Décimo Segundo Camelo em Luhmann, bem como a questão (a)metodológica da desconstrução na filosofia de Derrida e o construtivismo radical do conceito de forma de diferença que Luhmann toma da matemática de Spencer Brown. Tratam-se de questões igualmente interessantes. Entretanto, nesse artigo, a investigação pretende se concentrar em outras peças teóricas que aproximam Luhmann e Derrida, quais sejam: a singularidade e o poder ou, como podemos dizer, o poder da singularidade.

Em tempos de multiculturalismo, mundialização das relações sociais e globalização da comunicação, torna-se importante repensar a questão da singularidade e do poder da autoridade sobre as singularidades. Luhmann e Derrida ajudam a entender - e a desconstruir - os fundamentos místicos de uma autoridade política que supõe uma homogeneidade social, a partir da qual toda a singularidade é vista como desvio, como erro ou como inimigo, para promover exatamente essa mesma homogeneidade social. Diferentemente das concepções humanistas de sujeito, tanto em Luhmann quanto em Derrida a singularidade do sujeito é tratada com muito mais cuidado, com muito mais complexidade, sem nenhuma pretensão hegemônica ou hierárquica de definição ideológica de um conceito humanista-europeu-burguês de ser humano. Pelo contrário, tanto em Derrida quanto em Luhmann encontramos a singularidade a partir da diferença. A identidade a partir da diversidade. E concepções teóricas que renunciam tanto ao pensamento metafísico, quanto ao pensamento ontológico, conseguem desenvolver esse nível de intelecção a respeito dos problemas jurídicos relacionados à questão da diversidade, da singularidade, da identidade e, do outro lado, a questão do poder da autoridade sobre essa diversidade.

Para tanto, no primeiro capítulo tratará de como os autores operam as suas teorias que contemplam grande potencial de ruptura, em que objetiva-se estabelecer uma aproximação dialética entre as noções de desconstrução em Derrida e observação de segunda ordem em Luhmann, de modo a refletir sobre as proximidades e divergências dessas duas teorias no que tange às suas pretensões (a)metódicas.

No segundo e terceiro capítulo pretende-se comparar os conceitos de identidade e de singularidade, bem como as noções de autoridade e poder, explicitando seus potenciais intelectivos e explorando possibilidades de diálogo entre eles. Ao fim, faz a mediação entre os conceitos expostos no segundo e terceiro capítulo, realizando possível aproximação quando trata da ideia de singularidade/identidade e complementaridade tratando da ideia depoder/autoridade.

\section{DESCONSTRUÇÃO, PARADOXO E OBSERVAÇÃO}

Muitas aproximações podem ser realizadas entre os conceitos de Derrida e de Luhmann. Entretanto, tratam-se de perspectivas teóricas tão diferentes que essas aproximações apresentam-se mais como metáforas do que como análises de nível conceitual. Naturalmente, Derrida desenvolve uma filosofia que não apenas não conta 


\section{Quaestio Iuris}

vol. 09, n. 02, Rio de Janeiro, 2016. pp.637-651

DOI: $10.12957 /$ rqi.2016.18229

com metodologia, mas principalmente a nega pela desconstrução, enquanto que Luhmann desenvolve um esquema de observação que tem uma certa pretensão metodológica. Não uma metodologia no sentido tradicional, claro, mas há em Luhmann um esforço metódico de garantir um certo nível de cientificidade e de verificação empírica nas descrições decorrentes do uso da sua rede conceitual. Esforço esse que não se encontra em Derrida.

Queremos demonstrar, contudo, que a desconstrução presente no pensamento de Derrida é bastante próxima da noção de paradoxo em Luhmann, especialmente na fase que incorpora a partir do início dos anos noventa, com a publicação da sua obra A ciência da Sociedade ${ }^{6}$. A partir dessa obra, que foi originalmente publicada em 1990, a categoria do paradoxo torna-se tão importante quanto os conceitos de autopoiese, autoreferência e observação.

Para Luhmann, observar é distinguir. E distinguir é traçar uma diferença entre o que se indica e todo o restante das possibilidades de indicação. Por isso, toda observação é uma operação que tem, em si, um paradoxo: o paradoxo da auto-observação. E desse modo, toda observação possui uma potência desconstrutiva, uma potência de introduzir uma distinção diferente naquilo que se havia comodistinto.

Uma ilustração exemplar disso acontece logo após à publicação de A ciência da Sociedade, quando Luhmann publica o seu Sociologia do Risco ${ }^{7}$. Luhmann desconstrói completamente a noção de risco como diferença da segurança, presente na semântica científica moderna, e a reconstrói por meio da introdução de outra diferença: o risco como diferença do perigo ${ }^{8}$. Risco e perigo então se desconectam da noção de segurança e se reconectam a outros elementos de sentido, como é o caso da tensão entre a perspectiva dos decisores (que assumem os riscos) e a dos afetados (que sofrem os perigos). Assim, Luhmann não só desenvolve um novo e bastante original conceito de risco, como também ilustra as possibilidades de desconstrução e de reconstrução presentes no esquema de observação diferencialista da sua teoria dos sistemas.

Ao explicitar como a sociedade introduz distinções criativas para desdobrar paradoxos da comunicação, a observação de segunda ordem da teoria dos sistemas, portanto se estabelece sobre uma base radicalmente construtivista. Isso, contudo, não significa nenhuma contradição com o pensamento desconstrutivista de Derrida. Pelo contrário, o construtivismo radical é também um modo de desconstrução ereconstrução.

Referindo-se expressamente aos conceitos de escritura e filosofia de Derrida, Luhmann observa que não apenas algo arbitrário pode ser desconstruído, mas também a desconstrução em si pode ser desconstruída, não levando a lugar algum. Muito embora a desconstrução também possa ser ela mesma desconstruída, o paradoxo que está na origem de toda forma de comunicação, por outro lado, permite ir além da desconstrução. Permite

${ }^{6}$ LUHMANN, Niklas. La Ciencia de la Sociedad. Tradução de Javier Torres Nafarrate. México: Universidad Iberoamericana, 1996.

${ }^{7}$ LUHMANN, Niklas. Sociologia del rischio. Tradução de Giancarlo Corsi. Milano: Bruno Mondadori, 1996.

${ }^{8}$ Ibidem, p. 33. 
entender como uma distinção se torna operativa quando, por força do paradoxo, ela precisa criar a si mesma a partir de si mesma - autopoiese. Por conseguinte, diferentemente de Derrida, Luhmann prefere descrever, como um observador de segunda ordem, as formas de distinção que desenvolvem os paradoxos, que desdobram os paradoxos de modo a torna-los invisíveis, assimetrizados. ${ }^{9}$

Em outro trecho Niklas Luhmann, tratando da desconstrução, comenta que ela deveria ser entendida de forma mais prática, enquanto um tipo de método, como fazem cientistas norte-americanos que vão além das questões literárias, aplicando a algumas questões relativas ao direito. No entanto, aponta que o seu sentido originário posto por Jacques Derrida é propositalmente vago. ${ }^{10}$

Nesse sentido, é importante esclarecer duas questões. Primeiramente, Derrida afirma que a desconstrução não se trata de um método porque ele é justamente contrário a fórmulas e enquadramentos, o que recairia em vícios metafísicos da modernidade, sendo prejudicial à justiça que é incalculável. Derrida inclusive sublinha que "o momento da decisão é uma loucura. ", fazendo referência à Kierkegaard. ${ }^{11}$ Todavia, não por ser um método é que deixa de cumprir uma função prática e de ir além da desconstrução de texto apenas, sendo esta a segunda questão.

Muitos autores tratam a desconstrução derridiana apenas de forma literária, desconsiderando todo o seu potencial crítico e intelectivo no campo da filosofia, da sociologia e da ciência em geral. Mas não se deve limitar a desconstrução apenas a uma forma de crítica literária. Deve-se tomar de forma cuidadosa a leitura de Jacques Derrida, a fim de que não se cometa equívocos e esclareça como se trata a desconstrução em uma perspectiva não apenas gramatical, pretendendo a desconstrução para além da escritura enquanto texto. Embora seu objetivo inicial, aparentemente, relaciona-se a desconstrução de textos, do significante e significado, haja vista seu esforço em destacar a importância do texto escrito em Gramatologia. ${ }^{12}$

Para tanto, faz-se referência à passagem em que Derrida aponta que os trabalhos de Stanley Fish, Barbara Herrstein-Smith, Drucilla Cornel, Samuel Weber que tratam da articulação entre literatura, filosofia, direito e problemas políticos-institucionais são os mais fecundos e mais necessários. Prossegue indicando que seriam os programas mais radicais da desconstrução, de forma a tornar possível que ela não se feche nela mesmo, fazendo discurso puramente especulativo, fechado, preso à academia, mas pretende "mudar as coisas e intervir no mundo de modo eficiente e responsável, naquilo que chama de cidade, a polis." ${ }^{\text {13 }}$

\footnotetext{
${ }^{9}$ LUHMANN, Niklas. El Derecho de la Sociedad. Tradução de Javier Torres Nafarrate. México: Universidad Iberoamericana, 2005 , p.397.

${ }^{10}$ Ibidem, p. 264

${ }^{11}$ DERRIDA, Jacques. Força de Lei.Tradução de Leyla Perrone Moisés. São Paulo: Martins Fontes, 2010, p. 57.

${ }^{12}$ DERRIDA, Jacques. Gramatologia. Tradução de Miriam Chnaiderman e Renato Janine Ribeiro. São Paulo: Perspectiva, 2013.

${ }^{13}$ DERRIDA, Jacques. Força de Lei. Tradução de Leyla Perrone Moisés. São Paulo: Martins Fontes, 2010, p. 14. _vol.09, n. 02, Rio de Janeiro, 2016. pp. 637-651
} 
Ainda, tratando da desconstrução de forma mais filosófica, Derrida afirma ser urgente atentar para o desenvolvimento concorrente do conjunto da desconstrução. Aparentemente, foi o que ele fez em Força de Lei, cujo objetivo é a desconstrução do direito como possibilidade de justiça ${ }^{14}$ e não como um mero texto literário. Pergunta-se: qual texto Derrida desconstrói em Força de Lei? Não se encontra resposta para tanto. A desconstrução de Derrida pode ser operada sobre qualquer tipo de discurso de fundamentação, qualquer discurso de autoridade. O signo, no desconstrutivismo de Derrida, só se mantém como uma unidade analítica por uma mera "complicité métaphysique" 15 , que deve ser renunciada.

Considerando a possibilidade de desconstrução para além do texto, deve-se entender que a desconstrução é um apelo à responsabilidade diante da memória, que regula a justiça e a justeza do comportamento, ao passo que a desconstrução age segundo dois estilos, que na maioria das vezes se complementam um ao outro. De um lado, tem-se a tarefa de uma memória histórica e interpretativa, no sentido de ser uma herança de um imperativo ou de um feixe de injunções, que procede por leituras de textos e interpretações genealógicas. De outro, o aspecto demonstrativo e aparentemente não histórico de paradoxos lógicos formais. ${ }^{16}$

Tal como a observação de segunda ordem da teoria dos sistemas de Luhmann, a desconstrução de Derrida também não é linear, nem ao menos fornece um método a qual seguir, fórmulas mágicas para se chegar a uma conclusão única que satisfaça o homem moderno. Quem espera ou necessita de segurança epistêmica, certamente não a encontrará em uma teoria desse quilate: trata-se de uma teoria pós-ontológica, assim como a teoria dos sistemas de Niklas Luhmann.

A teoria dos sistemas é de grande nível de abstração e também apresenta uma proposta pós-ontológica de entendimento das relações sociais. Não se parte das coisas, entidades, objetos ou signos lingüísticos, mas de distinções como a sua unidade analítica. Vale dizer que é uma teoria sem princípios, sem uma estrutura hierárquica e sem uma linearidade metodológica, sendo, principalmente, rede de conceitos.

Luhmann inicia o desenvolvimento de sua teoria abordando a ideia de sistemas, que seriam o conjunto de operações e eventos que se mantém em certa continuidade no tempo. Passa também pelo conceito de sistemas autorreferenciais, que designa a reprodução do sistema através da diferenciação entre ambiente e sistema, mas sendo operacionalmente fechado, produz a causa de si mesmo. Todavia, tem a sua sofisticação teórica com o desenvolvimento dos sistemas autopoiéticos.

Cabe destaque que o sistema autopoiético é a possibilidade de diferenciação do sistema e seu ambiente, identificando a si próprio como sistema, os quais produzem não somente as suas estruturas, mas também seus

\footnotetext{
${ }^{14}$ Ibidem, p. 10, 15.

${ }^{15}$ DERRIDA, Jacques. La structure, le signe e le jeu. In: L'écriture et la différence. Paris: Édition du Seuil, 1967, p.413.

${ }^{16}$ DERRIDA, Jacques. Força de Lei. Tradução de Leyla Perrone Moisés. São Paulo: Martins Fontes, 2010, p.37,38,41.
} 
elementos que o constituem. Assim, suas operações relacionam-se tanto com a identidade, quanto com a diferença. Pois na perspectiva pós-ontológica da diferença como forma de distinção, a identidade não está baseada em princípios, valores ou unidades ônticas, mas sim na diferença: a identidade a partir dadiferença.

O conceito de forma de Spencer Brown ${ }^{17}$ ajuda a entender essa estratégia pós-ontológica, diferencialista, do esquema de observação da teoria dos sistemas de Luhmann. Forma é uma forma de diferença entre o que se indica e o que não se indica, mas que exatamente por isso fica como um pressuposto implícito da identidade do que foi indicado. Assim, uma forma designa tanto o marked space quanto o unmarked space, tanto o lado indicado, da identidade, quanto o lado não indicado e implícito, da diferença em relação a outras coisas. O observador de segunda ordem é um paradoxo, uma reentry no sentido de Spencer Brown ${ }^{18}$. Um ato de introduzir uma distinção naquilo que já se tinha por distinguido.

Em termos metódicos, isso significa observar as formas de comunicação da sociedade como o resultado contingente de distinções que poderiam ter sido diferentes. Significa observar que a diferença entre direito e sociedade ou sociedade e Estado, por exemplo, são distinções realizadas como estratégia de desdobramento de paradoxos nos fundamentos do direito, da sociedade e do Estado. Basta verificar como a semântica jurídica fundamenta o direito em uma leitura política das constituições, enquanto as mesmas constituições sofrem uma leitura paradoxalmente jurídica para fundamentar a política da sociedade. A mesma constituição então é um mesmo e diferente fundamento para dois sistemas que se fundamentam um ao outro, sem uma origem absoluta ou um fim necessário.

O poder de desconstrução da observação de segunda ordem de Luhmann é, portanto, equiparável à desconstrução da filosofia de Derrida. Não só em termos de analogia ou em termos meramente metafóricos. A desconstrução de Derrida e a observação das estratégias sociais de assimetrização de paradoxos em Luhmann são muito próximas também em termos de resultados intelectivos. A diferença é que em Luhmann pode ser encontrado um esforço metodológico de análise baseado na diferença entre estrutura social e semântica dos sistemas, enquanto que em Derrida, longe de uma pretensão metodológica, a desconstrução apresenta-se mais como uma filosofia, uma reflexão, um modo de conhecer.

\section{IDENTIDADE E SINGULARIDADE}

Ao que se apresenta, ainda que de forma implícita, tem-se a ideia de singularidade em Luhmann e explicitamente em Jacques Derrida, que leva à complexidade da interpretação jurídica. Nesse sentido é que se verificam as múltiplas possibilidades de aplicação do direito na sociedade, uma vez que sua complexidade,

\footnotetext{
${ }^{17}$ SPENCER-BROWN, George. Laws of forms. New York: Dutton, 1979, p. 1.

${ }^{18}$ Ibidem, p. 25.
} _vol.09, nº. 02, Rio de Janeiro, 2016.pp. 637-651 
contingência e problemas de legitimidade generalizada decorrem, principalmente, da questão da singularidade. Afinal, não vivemos mais sob um suposto de povo homogêneo, igual, com uma mesma e única cultura de princípios, valores e hábitos intersubjetivamente compartilhados. Pelo contrário, a sociedade contemporânea se caracteriza mais pela coexistência de múltiplos singulares, que fazem existir a pluralidade, logo a diversidade e mais ainda: a complexidade.

Como pista de assimilação da singularidade na teoria dos sistemas, quando Luhmann trata da crítica à sociologia, ele procura justificar a criação de uma teoria da sociedade capaz de ser universal, mas ao mesmo tempo específica ${ }^{19}$. Acredita que o humanismo absolutiza no sentido de que homogeniza o sujeito. Por isso as teorias sociológicas tradicionais não percebem que as pessoas são diferentes e com diferenças merecem ser tratadas.

Ainda que de forma implícita, Niklas Luhmann trata do observador de segunda ordem transitando sobre a questão da singularidade, pois decorrente dela ocorrem as inúmeras possibilidades de observação. Conforme expõe Gunther Teubner, a observação de segundo grau destrói toda identidade fixa, de modo que os diversos ambientes do direito constroem ficções particulares. Ou seja, "a identidade do direito transforma-se à maneira de um camaleão segundo os seus contextos de observação. ${ }^{{ }^{20} \mathrm{O}}$ que vale dizer que haverá inúmeras interpretações decorrentes da posição do observador, que sempre será único no sentido de narrativa de vida. Ainda Teubner sintetiza afirmando que "A observação de segundo grau é o paralelo sistêmico da decomposição desconstrutora do direito, da sua dissolução numa multiplicidade contraditória de significações “21

Na perspectiva de Jacques Derrida, quando trata da desconstrução enquanto possibilidade de justiça, destaca que a justiça só pode ocorrer se endereçada ao outro. Esse endereço é sempre singular, enquanto o direito sempre supõe a generalidade de uma regra. Nesse sentido, Derrida, apoiado na ideia de Emmanuel Levinas no livro Totalité et infini, ${ }^{22}$ entende que a justiça é a relação com o outro. Assim, a justiça para Derrida só pode vir a acontecer se for dirigida ao outro, na irredutível e infinita singularidade. ${ }^{23}$

Observa-se a singularidade de forma inversa nas teorias. Para Derrida a singularidade é dada a quem se observa para destinar a justiça, mas não retirando a singularidade daquele que observa para endereçar a justiça (embora não trate da questão de modo explícito).

Para Luhmann, a singularidade é posta por aquele que observa, a singularidade é condição de possibilidade da identidade e da diferença no ato de observar, no ato de distinguir entre sistema e ambiente. Devese fazer ressalva de que Luhmann não fala de singularidade do observador no sentido de um sujeito, de um

\footnotetext{
${ }^{19}$ LUHMANN, Niklas. La Sociedade de la Sociedade. Tradução Javier Torres Nafarrate. México: Universidad Iberoamericana, 2006.p. 05 .

${ }^{20}$ TEUBNER, Gunther. Os Múltiplos corpos do Rei: A autodestruição da hierarquia do direito. In: Filosofia do Direito e do

Direito Econômico. Que diálogo? Lisboa: Piaget, 2001,p.399.

${ }^{21}$ Ibidem, p.340.

${ }^{22}$ LÉVINAS, Emmanuel. Totalidade e Infinito. Tradução de José Pinto Ribeiro. Lisboa: Edições 70, 1980.

${ }^{23}$ DERRIDA, Jacques. Força de Lei. Tradução de Leyla Perrone Moisés. São Paulo: Martins Fontes, 2010, p.42.
} 
indivíduo ou de um humano, mas trata da questão do observador como um sistema dotado da capacidade de transitar de modo seletivo entre auto eheterobservação. ${ }^{24}$

Sistemas biológicos fazem isso. Sistemas de consciência também. A novidade e a originalidade de Luhmann está em demonstrar que há também sistemas sociais dotados dessa capacidade de auto-observação, sistemas que processam comunicação com base nas comunicações precedentes e, assim, constroem a história e a si mesmos como produto de suas próprias operações.

A singularidade, portanto, embora seja um conceito mais ligado à filosofia social e política, pode ser facilmente incorporada também na rede conceitual da teoria dos sistemas autopoiéticos de Niklas Luhmann, seja sob a metáfora da policontexturalidade no nível dos sistemas sociais, seja pela noção de observação de segunda ordem no nível da unidade analítica da teoria.

\section{A AUTORIDADE E O PODER}

No aspecto do poder, deve-se inicialmente fazer ressalvas. Há dificuldade de assimilar o poder em Luhmann e Derrida. Primeiramente, porque na Teoria dos Sistemas há a divisão em sistemas sociais, nos interessando aqui o sistema político e o sistema jurídico. Diferentemente, em Jacques Derrida não há divisão em sistemas, em uma interpretação ativa (assim permitida pelo próprio Derrida quando trata da teoria de Montaigne e Pascal ${ }^{25}$ ), o fundamento místico de autoridade estaria inserido no sistema jurídico e político, devendo se justificar:

Jacques Derrida afirma que não se obedecem às leis porque são justas, mas porque tem autoridade. Ampliando essa abordagem, aponta que o momento instituidor do direito é uma força performativa, um apelo à crença, pois necessita-se acreditar nela para que possa continuar a existir. ${ }^{26}$

Para entender a autoridade em Jacques Derrida, deve-se tratar da força da lei. A lei carrega em si força, que pode ser "direta ou não, física ou simbólica, exterior ou interior, brutal ou sutilmente discursiva - ou hermenêutica -, coercitiva ou reguladora etc. ${ }^{\text {"27}}$ Mas o que faz a força ser justa ou não violenta é a legitimidade que possui, o que vale dizer: se há autoridade justificada. A força é entendida como força diferida, performativa, persuasiva, de retórica e de crença. ${ }^{28}$

O golpe de força só seria possível pela autoridade, e, nesse sentido, fazendo a releitura de Pascal e Montaigne, Derrida estabelece o fundamento místico de autoridade. $\mathrm{O}$ ato instituidor do direito seria um golpe

\footnotetext{
${ }^{24}$ LUHMANN, Niklas. El Derecho de la Sociedad. Tradução de Javier Torres Nafarrate. México: Universidad Iberoamericana, 2005, p. 264.

${ }^{25}$ DERRIDA, Jacques. Força de Lei. Tradução de Leyla Perrone Moisés. São Paulo: Martins Fontes, 2010, p. 25.

${ }^{26}$ Ibidem, p. 21, 24.

${ }^{27}$ Ibidem, p. 24.

${ }^{28}$ Ibidem, p. 9, 11.
} 
de violência sem fundamento. Um golpe de violência performativa, não podendo se dizer justa nem injusta. Perfazendo o místico, em um silêncio fechado, fruto ele mesmo do golpe de violência fundador. $\mathrm{O}$ místico seria a origem de toda instituição.

O que se depreende do texto é que a força da lei, de sua produção (no campo político) e de sua aplicação (campo jurídico), está diretamente relacionada ao fundamento místico de autoridade, com a instituição da autoridade..$^{29}$ Assim, o ato instituidor estaria concentrado na autoridade concedida através do golpe de violência, tanto no plano político, quanto no plano jurídico. Tem-se a aporia de todas as instituições e suas representações. Há que se ressaltar que este fundamento místico de autoridade não é metafísico, mas algo performativo.

Já Niklas Luhmann prefere entender o ato instituidor da autoridade ou do poder sob a ótica dos meios de comunicação simbolicamente generalizados, os quais selecionam as possibilidades de aceitação e de negação a uma pretensão de poder. Conceitua o poder de forma ampla, como uma forma de comunicação que faz com que haja a veiculação de uma escolha limitada, imposta pelo poderoso, indo além da ideia de poder como um recurso do Estado Nacional enquanto um poder político relacionado à coação. ${ }^{30}$

É importante entender o poder enquanto relacionado à escolha. Discorre Luhmann que relações de poder se tornam projetos bastante complexos, pois é necessário fundamentar uma medida pluridimensional da complexidade das possibilidades que se pode escolher. Ou seja, o poder cresce com liberdades de ambos os lados, aumenta na medida em que gera alternativas. ${ }^{31}$ Diferentemente da violência, que coage a pessoa a fazer o deixar de fazer alguma coisa, o poder acontece de modo muito mais sutil: o poder mantém, para o submisso, as alternativas entre cumprir ou descumprir a ordem, mas atribui consequências indesejáveis à alternativa do descumprimento. O poder deixa uma margem de escolha entre obedecer e não obedecer. E restringe todo o restante das possibilidades.

Destaca-se que a Política, poder, força, Estado, são conceitos diferentes na teoria dos sistemas. Assim, a força é um, dentre outros, recursos do poder. O poder é o meio de comunicação da política que funciona através do código obedecer ou não obedecer, mas ainda assim submetido ao poder. Enquanto o Estado é o sistema de organização do poder político. O Estado é o símbolo que designa as organizações que atualizam o sistema político da sociedade. E a política é o sistema que produz e reproduz todas essasoperações.

Assim, diferentemente de Derrida, para quem o poder possui um fundamento místico de autoridade, para Luhmann, o fundamento do poder é um problema genuinamente social e historicamente bem consolidado, qual seja: o problema da coordenação das ações. Tal como o problema da escassez desencadeia meios de

\footnotetext{
${ }^{29}$ Ibidem, p. 24, 25.

${ }^{30}$ LUHMANN, NIlkas. Poder. Tradução de Martine Creusot de Rezende Martins. Brasília: Editora Universidade de Brasília, 1985, p. 08 .

${ }^{31}$ Ibidem, p. 09.
} 
comunicação da economia, como o dinheiro e a propriedade; tal como o problema da generalização congruente de expectativas desencadeia meios de comunicação do direito, como as leis, precedentes e demais fontes válidas de direito; tal como a questão da verdade objetiva - da correspondência intersubjetiva de impressões sobre um mesmo e único mundo objetivo - desencadeia métodos científicos; também o poder encontra, em Luhmann, um fundamento prático na experiência histórica da sociedade mundial.

Enquanto um meio de comunicação generalizado simbolicamente, o poder carrega consigo, sempre, o paradoxo do seu próprio fundamento. E nesse sentido, Luhmann e Derrida se tornam muito próximos. Pois do mesmo modo que em Derrida o poder da autoridade só pode se fundamentar em um mitologema, também em Luhmann, o fundamento da autoridade, por constituir um paradoxo, precisa ser assimetrizado mediante a introdução criativa de valores exteriores ao sistema de referência. Mediante suplementos. E nada mais místico do que essa atitude criativa de suplementar o vazio de sentido produzido pelo paradoxo do poder, mediante uma referência, por exemplo, ao poder econômico, poder religioso, poder da verdade, poder da informação etc.

Em Luhmann, o fundamento do poder também é um fundamento místico, mas não no sentido metafísico e sim no sentido de que o poder, como qualquer outro meio de comunicação simbolicamente generalizado, repousa sobre um paradoxo, fundamenta-se a si mesmo a partir de si mesmo, sem uma finalidade necessária ou uma origem absoluta. Essa ausência de fundamento se mistifica, contudo, mediante a introdução de uma distinção criativa, contingente e arriscada: em cada época histórica, o fundamento do poder político do Estado transita sob autoridades distintas. E mesmo hoje, quando o poder parece se diluir entre organizações da sociedade civil, empresas transnacionais, organizações políticas transnacionais, ainda assim acreditamos em um fundamento místico da autoridade do direito endereçado a um conceito político de constituição.

\section{APROXIMAÇÃO E COMPLEMENTARIDADE DAS TEORIAS}

Fala-se de aproximação quando trata da ideia de singularidade/identidade e complementaridade tratando da ideia de poder/autoridade.

É possível uma aproximação bastante sensível entre a noção de identidade em Niklas Luhmann com a singularidade em Jacques Derrida. Obviamente, ressalvadas as enormes diferenças em termos de scripts teóricos, de objetivos e de justificativas, ambos compartilham o entendimento e a preocupação de elaborar uma teoria não linear, sem forma rígida e sem características ontológicas, para desse modo privilegiar uma das coisas mais importantes para o entendimento do mundo contemporâneo: a pluralidade. Ou seja, é válido dizer que só existe o plural porque existem milhares de singulares, únicos e irredutíveis, que não cabem em uma forma de sistema jurídico, ainda mais monojurídico, ou em uma regra matemática imposta, principalmente, por matrizes 
macroeconômicas. Em decorrência desse fato, revela-se a especial importância de se pensar um pluralismo jurídico, capaz de, ao menos, levar a aplicação do direito de forma mais justa no sentido derridiano.

Quanto ao poder e a autoridade, deve-se atentar inicialmente que o poder pode ser entendido de diversas formas e que pretender uma unificação conceitual do poder já é uma pretensão de poder. Tomando a ressalva, justifica-se que a pretensão é de lançar questionamento sobre a possibilidade de complementação da teoria dos sistemas e da desconstrução quanto a reprodução do sistema político para a manutenção do mesmo, decorrente da necessidade de a sociedade creditar autoridade ao sistemapolítico.

Verifica-se que em Niklas Luhmann o poder é contingente, relacionado à escolha, enquanto não existe um fundamento em si, pois seu fundamento material é, no fundo, um paradoxo, uma diferença autoconstitutiva, autológica, um différance no sentido de Derrida ${ }^{32}$. Por outro lado, o poder em Derrida apresenta-se enquanto algo performativo, que necessita de que pessoas creditem autoridade para que exista. Para entendimento, nada melhor de que esta frase para explicar a estrutura performativa do direito e da autoridade de forma geral posta por Derrida: "Digo que te falo, dirijo-me a ti para dizer-te que isto é verdade, que é assim, prometo-te ou renovo a promessa de fazer uma frase e de assinar o que digo quando digo o que te digo ou tento dizer-te a verdade." ${ }^{33}$

No caso exposto, a ideia de autoridade e poder não se chocam, não são opostas, pois a autoridade em Derrida é posta como a instituição do Estado em um muro cercado pelo golpe de violência, enquanto que Luhmann já trata como capacidade de impor escolhas por aquele que detém o poder, situado dentro ou fora do Estado. No entanto, observa-se que o sistema político, no qual está inserida a comunicação do poder, é um sistema dotado de autopoiese. Nesse sentido, é válido lembrar que a função de um sistema pode ser entendida autorreferencialmente como a função de manter a sua própria funcionalidade. E isso significa: manter a sua própria autopoiese. O que se quer dizer é que a reprodução do sistema político é dada para garantir a sua própria sobrevivência, haja vista que é necessário que a sociedade acredite em sua autoridade para que continue a existir.

Vale lembrar, como exemplo, o episódio das manifestações de julho de 2013 no Brasil, que, em resposta, no sentido de manutenção do sistema político, foi votada pelo Congresso Federal e sancionada pelo Executivo a Lei $n^{\circ} 12.846$, de $1^{\circ}$ de agosto de 2013, a qual responsabiliza pessoas jurídicas pela prática de atos contra a administração pública, nacional ou estrangeira. Não obstante, há a tentativa de realizar a Reforma Política pelo Congresso Nacional a fim de manterem seu crédito, uma vez que se percebem críticas da sociedade quanto as normas eleitorais. Ou seja, observa-se a movimentação - a reprodução - do sistema político para que não deixe de existir, pois precisa do crédito, o que caracteriza o fundamento místico da sua própria autoridade.

\footnotetext{
${ }^{32}$ DERRIDA, Jacques. La Différance. In: Marges de la philosophie. Paris: Éditions de Minuit, 1972, p. 1.

${ }^{33}$ DERRIDA, Jacques. Força de Lei. Tradução de Leyla Perrone Moisés. São Paulo: Martins Fontes, 2010, p. 53. _vol.09, n. 02, Rio de Janeiro, 2016. pp. 637-651
} 


\section{CONSIDERAÇÕES FINAIS}

Parra Derrida, a singularidade só pode ser entendida enquanto referência à alteridade, enquanto referência ao outro. Uma singularidade, portanto, a partir da alteridade. Em Luhmann, o singular também só pode ser entendido a partir da diferença. Mas não restringe o entendimento dessa diferença apenas à alteridade. Para Luhmann, a singularidade repousa sobre o paradoxo da diferença entre o singular e o plural - ou a singularidade e a alteridade.

A identidade de um sistema está tanto no sistema mesmo quanto no seu ambiente. Pois sistemas que processam comunicação são dotados da capacidade de combinar, de modo seletivo, tanto a autoreferência quanto referências externas. Assim, a identidade em Luhmann é produto do próprio sistema que opera em um ambiente. Do mesmo modo que em Derrida a singularidade só existe diante da alteridade, também em Luhmann um sistema - uma unidade, um sentido, uma identidade - só existe diante de um ambiente diferente, de um ambiente muito mais complexo e incontrolável para o sistema, de um ambiente que, do ponto de vista do sistema, é ruído sem um sentido estruturado.

A singularidade então precisa da alteridade, do mesmo modo que a identidade precisa da diferença. E isso rompe não apenas com a tradição metafísica do pensamento ocidental que acredita em uma "natureza das coisas", como também rompe com a própria ideia de que "existem coisas" no mundo independentemente do sentido comunicativo que fazemos delas ou sobre elas. Isso porque, quando se recompreende a singularidade do sujeito a partir da alteridade, bem como a identidade a partir da diferença, entende-se que a diversidade, ao contrário de ser um problema, um desvio, um erro, um atraso ou uma violência, é, na verdade, uma condição de possibilidade da própria estruturação da singularidade/identidade.

A singularidade só faz sentido a partir da alteridade, do mesmo modo como a identidade de um sistema só faz sentido a partir da diferença entre ele e o ambiente. Essa sucinta aproximação demonstra o quanto Derrida e Luhmann se encontram inseridos em um estilo de pensamento diferencialista, pós-ontológico, radicalmente antimetafísico e não homogeneizante do sujeito individual.

Como repensar então o poder da autoridade quando pensamos na singularidade/identidade como diferença em relação à alteridade/diferença? Como entender o poder da autoridade sobre uma singularidade que não se permite mais entender como uma massa amorfa que se convencionou chamar de povo? Não mais como uma soma de indivíduos humanos iguais, homogêneos e intersubjetivamente conectados por um mesmo mundo vivido que dita o que é autêntico e o que éinautêutico?

A desconstrução da filosofia de Derrida demonstra cair por terra esse fundamento místico da autoridade do poder, quando o crédito contratualista que a sociedade concedia ao soberano começa a apresentar sintomas de inadimplência. Foi exatamente isso que aconteceu nos protestos de junho de 2013. Sem uma temática bem 
definida, sem um objetivo previamente negociado, sem um fundamento ideológico ou partidário a estruturar os movimentos de protestos, a singularidade do protesto na diversidade dos seus motivos demonstrou que o crédito da autoridade política do Estado já não se reproduz mais baseado apenas nas mistificações tradicionais do voto, da representação democrática e da propaganda política-partidária. O poder da autoridade só pode ser entendido como um poder da singularidade. Um poder, portanto, que não pode supor uma homogeneização, uma classe, um estrato ou um grupo social hegemônico. Mas sim um poder de autoridade que pressupõe a alteridade, que pressupõe a diferença como condição da sua própria legitimidade.

Nesse sentido, torna-se possível repensar a questão da legitimidade democrática da autoridade política em termos de alteridade, em termos de diferença. Pois o governo não é só a soma de todos os indivíduos que fazem parte do governo, mas também e especialmente a oposição. Um governo é a diferença entre governo e oposição. O poder da autoridade não está, portanto, apenas na autoridade, mas também naquilo que a constitui como o outro lado da distinção: a singularidade de quem a ela sesubmeteu.

\title{
JACQUES DERRIDA AND NIKLAS LUHMANN'S: APPROACHES AND COMPLEMENTARITIES IN UNIQUENESS AND POWER
}

\begin{abstract}
This research seeks to establish a dialectical approach between the concepts of identity and uniqueness, power and authority, in deconstructionist philosophy of Jacques Derrida and the theory of autopoietic social systems of Niklas Luhmann. These are two important theoretical conceptions of the late twentieth century, very different in their assumptions and goals, but very close in some respects. Although comparisons appear to be more in terms of metaphors than conceptual level, both Luhmann as Derrida allow a new way of understanding the uniqueness and power of authority. Because in both the singularity / identity can only be understood from the otherness / difference. So that the power and the paradoxes of authority, which historically could only be held through mystical foundations of authority, are in Luhmann and Derrida the possibility of a differentialist rationale, postontological, based on the difference itself, which constitutes its identity in otherness that gives meaning to uniqueness. With the help of them you can have greater ability to assign meaning the apparent fragmentation of the state, especially with regard to its institutions and the Political Representation.
\end{abstract}

Keywords: Jacques Derrida and Niklas Luhmann. Singularity. Identity. Power.Authority.

\section{REFERENCIAS}

DERRIDA, Jacques. L'écriture et la différence. Paris: Édition du Seuil, 1967.

Marges de la philosophie. Paris: Éditions de Minuit, 1972.

Força de Lei. Tradução de Leyla Perrone Moisés. São Paulo: Martins Fontes, 2010.

Gramatologia. Tradução de Miriam Chnaiderman e Renato Janine Ribeiro. São Paulo: Perspectiva, 2013. 
LÉVINAS, Emmanuel. Totalidade e Infinito. Tradução de José Pinto Ribeiro. Edições 70: Lisboa, 1980.

LUHMANN, Niklas. Poder. Tradução de Martine Creusot de Rezende Martins. Brasília: Editora Universidade de Brasília, 1985

Sociologia del rischio. Tradução de Giancarlo Corsi. Milano: Bruno Mondadori , 1996.

La Ciencia de la Sociedad. Tradução de Javier Torres Nafarrate. México: Universidad Iberoamericana, 1996. 2005.

El Derecho de la Sociedad. Tradução de Javier Torres Nafarrate. México: Universidad Iberoamericana,

La Sociedade de la Sociedade. Trad. Javier Torres Nafarrate. México: Universidad Iberoamericana, 2006.

SPENCER-BROWN, George. Laws of forms. New York: Dutton, 1979.

TEUBNER, Gunther. Os Múltiplos corpos do Rei: A autodestruição da hierarquia do direito. In: Filosofia do Direito e do Direito Econômico. Que diálogo? Lisboa: Piaget,2001.

Justiça Autosubversiva: Fórmula de contingência ou de transcendência do direito? Revista Eletrônica do

Curso de Direito - PUC Minas Serro, Belo Horizonte, n. 4.

Trabalhoenviadoem 17deagostode2015.

Aceitoem04denovembrode2015. 